\title{
Impact of the Number of Failed Therapeutic Regimes on the Development of Resistance Mutations to HIV-1 in Northeast Brazil
}

\author{
Melissa Soares Medeiros ${ }^{1,2,3}$, Érico Antônio Gomes Arruda ${ }^{2}$, Richard Littleton Guerrant ${ }^{3}$, \\ Christopher Cooley Brown ${ }^{3}$ and Aldo Ângelo Moreira Lima ${ }^{1,3}$ \\ ${ }^{1}$ Federal University of Ceará, Department of Pharmacology and Fisiology, Fortaleza, IBIMED; ${ }^{2}$ São José Infectious Diseases Hospital; \\ Fortaleza, CE, Brazil; University of Virginia, Center of Global Health, Charlottesville, VA, USA ${ }^{3}$
}

\begin{abstract}
Highly-potent antiretroviral therapy is necessary to avoid viral replication in HIV patients; however, it can favor the appearance of resistance mutations. The mutations 41L, 67N, 70R, 210W, 215Y/F, 219E/Q, 44D and 118I are defined as nucleoside analogous mutations (NAMs), because they affect the efficacy of all nucleoside reverse transcriptase inhibitors (NRTI). The mutation most frequently associated with non-nucleoside reverse transcriptase inhibitors (NNRTIs) is 103N. 33W/F, 82A/F/L/T, 84V and 90M are called protease inhibitor resistance-associated mutations (PRAM), because they are associated with resistance to several protease inhibitors (PI). This study evaluated the development of resistance mutations and examine the susceptibility of HIV with these mutations to antiretrovirals in HIV-1 patients who have failed one or more therapy regimes. Analyses were made of 101 genotypic tests of patients with therapeutic failure to 2 or 3-drug regimens with NRTI, NNRTI or PI. We used the Stanford database to define the susceptibility profile of the viruses. The samples were divided into three treatment-failure groups: first (F), second (S) and multi-failure (MF) to antiretroviral regimens, and we correlated these groups with resistance profiles and principal mutations. There was a significant increase in resistance mutations V82A/F/L/T, I84V, L90M, M41L, K70R, L210W, T215Y/F and K219Q/E in MF. We also found significantly higher resistance to zidovudine, didanosine, stavudine and abacavir in MF. There was no increase in resistance to tenofovir $(p=0.28)$ and lopinavir $(p=0.079)$ in MF. A high degree of resistance to NNRTIs was observed in all groups. Increased resistance mutations will affect future therapeutic options for HIV patients in Brazil because it results in a significant increase in resistance to antiretroviral drugs.
\end{abstract}

Key-Words: Mutation, HIV-1, failure therapy, antiretrovirals, resistance.

Mutations associated with resistance to Zidovudine (ZDV) were identified for the first time by Brendan Larder et al. more than a decade ago. They demonstrated that the mutations 41L, 67N, 70R, 210W, 215Y/F and 219E/Q accumulate during continuous exposure ZDV whenever there is inadequate viral suppression [1]. The mechanism of resistance promoted by these mutations was also found to be responsible for resistance to Stavudine (D4T) and Abacavir (ABV) [2,3]. Increasing numbers of mutations are associated with higher phenotypic resistance; these mutations also affect resistance to Zalcitabine (DDC), Didanosine (DDI), Lamivudine (3TC) and Tenofovir (TDF) [4,5]. Consequently, the mutations can be better defined as nucleoside analogous mutations (NAMs), since they compromise the entire nucleoside reverse transcriptase inhibitors (NRTI) class [6]. It has also been found that the number of mutations related to resistance is positively associated with the number of times that the antiretroviral regimen is changed [7]. Resistance to this class of drugs was also reported in naïve injectable-drug user patients in the postHAART era, leading us to worry about resistance transmission in such groups [8].

Received on 15 April 2007; revised 28 August 2007.

Address for correspondence: Dr. Melissa Soares Medeiros. Clinical Research Unit \& Institute of Biomedicine/Center for Global Health Department of Physiology and Pharmacology School of Medicine Federal University of Ceará. Phone: 55 (85) 3366-8545 or -8437. Email: alima@ufc.br or alima@baydenet.com.br. www.upcibimed.ufc.br

The Brazilian Journal of Infectious Diseases 2007;11(5):451-455. (C) 2007 by The Brazilian Journal of Infectious Diseases and Contexto Publishing. All rights reserved.
More recent studies have found mutations 44D and 118I in patients who have utilized ZDV and 3TC; these mutations are associated with high levels of resistance to ZDV and consequently are considered NAMs [9-11]. Separate from the NAMs, $184 \mathrm{~V}$ has been recognized as an important mutation in this class due to its high resistance to 3TC [5,12-15]. 103N is the mutation that occurs most frequently in the Non Nucleoside Reverse Transcriptase Inhibitors (NNRTI) group, conferring resistance to this entire class, maintaining viral fitness. Other important mutations in this class are 106M, 181C/I and 188C/L/ $\mathrm{H}$, which strongly contribute to resistance $[5,12,16,17]$. 90M has been isolated from patients using Saquinavir, Nelfinavir, Indinavir or Ritonavir [18]. This mutation confers or directly contributes to resistance to all Protease Inhibitors (PIs) and is related to cross resistance in this class $[18,19]$. Codon 63 is the most polymorphic part of the protease gene, L63P being common in viruses that have never been in contact with PIs [12,20,21]. Higher resistance to PIs is associated with an increasing number of the mutations called UPAMs (Universal Protease Inhibitor Associated Mutations), including 82L/T, 84V and 90M. The acronym PRAM (protease inhibitor resistance associated mutations) has also been used to describe a group of mutations, consisting of 33W/F, 82A/F/L/T, 84V and 90M, which are responsible for cross-resistance among PIs [22]. In most cases, the presence of one or two PRAMs is associated with limited susceptibility to PIs [23].

This study evaluated the effect of therapeutic failure accumulation on the development of resistance mutations to each class of antiretroviral drugs and examine how it correlates with the susceptibility profile of HIV-1 in patients. 


\section{Materials and Methods}

This retrospective study was made at the São José Infectious Diseases Hospital, from April 2002 to March 2004, on patients receiving antiretroviral therapy who presented with failing double or triple therapy regimens that included a NNRTI, and first or second virological failure of a triple-therapy regimen that included a PI. Genotypic tests were made on blood samples from 101 patients. Mutations were analyzed with the Stanford Database to define the antiretroviral susceptibility profile [24].

The sample was divided into three distinct groups of therapeutic failure to antiretroviral regimens: first, second and multi-failure (three or more failures). We examined the resistance profiles of the viruses in these patients and how they were associated with the main resistance mutations. A descriptive statistical analysis was carried out with SPSS version 11, and comparisons were made using the software Epi Info version 6, with 2x2 tables, with confidence interval values of $95 \%$, considering two standard deviations. The tests were defined as significant when the $p$ value was $<0.05$.

\section{Results}

When we examined prior utilization of antiretrovirals, we found that the percentage of patients who had used each drug was: $82.2 \%$ Zidovudine, 79.2\%Lamivudine, 64.4\%Stavudine, 77.2\% Didanosine, 10.9\% Zalcitabine, 27.7\% Efavirenz, 23.8\% Nevirapine, 43.6\% Nelfinavir, 27.7\% Indinavir, 9.9\% Saquinavir, 26.7\% Ritonavir, 4\% Lopinavir and 1\% Amprenavir. Atazanavir, Abacavir and Tenofovir were not utilized. The protease inhibitors presented a second resistance distribution profile (Figure 1). No significant differences were found in the degree of resistance antiretrovirals by viruses in patients with primary versus secondary failure $(\mathrm{p}>0.05)$. However, there was a significant difference in comparison with the patients who had multi-failure for all of the PIs ( $<<0.05)$, except Lopinavir ( $\mathrm{p}=0.079$, Table 1 ).

When we evaluated the PRAM mutation profile in therapeutic failure, we found no significant differences between primary and secondary-failure patients. Significant differences were observed between the primary and secondary-failure groups compared with the multi-failure subgroup for the mutations V82A/F/L/T, I84V and L90M (Table 2). The NRTIs resistance profile distribution can be seen in Figure 2. No significant differences were found in resistance to antiretrovirals in patients with primary versus secondary failure. However, there was a significant difference in comparison with the multi-failure patients group for the drugs Zidovudine, Didanosine, Stavudine and Abacavir. There was no significant difference between the second failure and multi-failure groups for Abacavir, as there was a high predominance of resistance in both groups. There was also high resistance in all three groups against Lamivudine $(\mathrm{p}=0.24)$ and Entricitabine $(\mathrm{p}=0.52)$. Tenofovir had a low resistance profile in all groups (Table 3 ).
We found no significant differences in the NAM mutation profile for the NRTIs between the groups with primary and secondary therapeutic failure, considering mutations on codons 69, K65R and M184V. There were also no significant differences between the secondary failure group and the multifailure group for the mutations D67N, E44D, V118I, M184V, K65R, in codon 69, and for K219Q/E (Table 4). However, M184V was present at a high frequency in all three groups. The difference was significant for the mutations M41L, K70R, L210W, T215Y/F, when comparing the groups with primary or secondary therapeutic failure and multi-failure, and for K219Q/ E between the subgroups with primary failure and multi-failure $(p<0.05)$. The resistance profile of the NNRTIs can be seen in Figure 3. Between, There were no significant differences in the frequencies of resistance to the various NNRTI drugs between the therapeutic-failure groups; resistance was high to all of them (Table 5). No significant differences were found in the frequencies of the main mutations (K103N, Y181C/I, $\mathrm{Y} 188 \mathrm{C} / \mathrm{L} / \mathrm{H}$ and G190A/S) in terms of HIV resistance to this class of drugs in the comparison of the groups with primary, secondary and multi-failure (Table 6).

\section{Discussion}

When we grouped the patients according to the number of therapeutic failures, the antiretroviral resistance profile that was that was evident in patients with primary and secondary failure depended on whether they were being treated with regimens with an NNRTI or a PI. Whenever these patients failed therapy, they were treated with a drug regimen from the other class of antivirals. For example, when a patient who was started on NNRTI experienced therapeutic failure, the NNRTI would be replaced with a member of the PI class. Similarly, when a patient who was started on a PI failed therapy, he would be switched to a member of the NNRTI group. As a result, we expected to find patients with minimal exposure to members of the PI class in both groups. In the group with three or more therapeutic failures, resistance to almost all of the PIs was significantly more frequent than in the other groups. This is likely a consequence of increased resistance associated with increased exposure $[25,26]$. We observed that the UPAM mutations V82A/F/L/T, I84V and L90M increased in frequency with increased numbers of therapeutic failures [27]. However, this was not observed for Lopinavir [28]. We found differences in resistance to the NRTI class of drugs in the multi-failure group compared with the primary and secondary failure groups. These differences probably occurred because with increasing numbers of therapeutic failures, there were more NAMs. When we compared resistance to Abacavir in the secondary-failure group versus the multi-failure group, we found a high frequency of resistance in both groups. Significant differences in resistance to Lamivudine ( $\mathrm{p}=.24)$ and Emtricitabine (.52) were also not seen ( $p=0.24$ and 0.52 , respectively); there was a high frequency of resistance in all three groups, probably because of the predominance of M184V (55.1\% in primary failures, 70.6\% in 
Table 1. Comparison of resistance profile to protease inhibitors organized in subgroups according to the number of therapeutic failures $(\mathrm{N}=101)$

\begin{tabular}{lccccrr}
\hline Antiretroviral & $\begin{array}{c}\text { First failure } \\
\text { \% (N) }\end{array}$ & $\begin{array}{c}\text { Second failure } \\
\mathbf{\%}(\mathbf{N})\end{array}$ & $\begin{array}{c}\text { pvalue } \\
\mathbf{1}^{\text {st }} \text { and } \\
\mathbf{2}^{\text {nd }} \text { failure) }\end{array}$ & $\begin{array}{c}\text { Multi-failure } \\
\mathbf{\%}(\mathbf{N})\end{array}$ & $\begin{array}{r}\text { pvalue } \\
\mathbf{1}^{\text {st }} \text { and } \\
\text { multi-failure) }\end{array}$ & $\begin{array}{c}\text { p value } \\
\mathbf{2}^{\text {nd }} \text { and } \\
\text { multi-failure) }\end{array}$ \\
\hline Nelfinavir & $20.4(10)$ & $18.9(7)$ & 0.86 & $86.7(13)$ & 0.0000029 & 0.0000054 \\
Ritonavir & $4.1(2)$ & $0(0)$ & 0.5 & $53.3(8)$ & 0.000051 & 0.0000086 \\
Indinavir & $6.1(3)$ & $0(0)$ & 0.25 & $53.3(8)$ & 0.00016 & 0.0000086 \\
Saquinavir & $2(1)$ & $0(0)$ & 1 & $46.7(7)$ & 0.000072 & 0.00048 \\
Amprenavir & $0(0)$ & $0(0)$ & 1 & $26.7(4)$ & 0.0021 & 0.005 \\
Lopinavir & $0(0)$ & $0(0)$ & 1 & $13.3(2)$ & 0.052 & 0.079 \\
Atazanavir & $2(1)$ & $00)$ & 1 & $40(6)$ & 0.0004 & 0.00024 \\
Total & 49 & 37 & - & 15 & - & - \\
\hline
\end{tabular}

Statistical analysis was carried out using the Chi-square test; however, when the sample size was less than five, we utilized the Fisher test.

Table 2. Percentage patients with Protease Resistance Associated Mutations in the therapeutic failure subgroups

\begin{tabular}{lccc}
\hline Resistance mutations & $\begin{array}{c}\text { pvalue } \\
\left.\mathbf{( 1}^{\text {st }} \text { and } \mathbf{2}^{\text {nd }} \text { failure }\right)\end{array}$ & $\begin{array}{c}\text { p value } \\
\left.\mathbf{( 2}^{\text {nd }} \text { and multi-failure }\right)\end{array}$ & $\begin{array}{c}\text { p value } \\
\left.\text { (1 }^{\text {st }} \text { and multi-failure }\right)\end{array}$ \\
\hline $\mathrm{L} 33 \mathrm{~W} / \mathrm{F}$ & 1 & 0.23 & 0.23 \\
$\mathrm{~V} 82 \mathrm{~A} / \mathrm{F} / \mathrm{L} / \mathrm{T}$ & 0.45 & 0.024 & 0.003 \\
$\mathrm{I} 84 \mathrm{~V}$ & 1 & 0.02 & 0.03 \\
$\mathrm{~L} 90 \mathrm{M}$ & 0.24 & 0.00008 & 0.0000003 \\
\hline
\end{tabular}

Statistical analysis was carried out using the Chi-square test; however, when the sample size was smaller than five we utilized the Fisher test.

Figure 1. Resistance profile to protease inhibitors based on genotypic analysis, using the stanford database $(\mathrm{N}=101)$, organized according to the number of therapeutic failures.

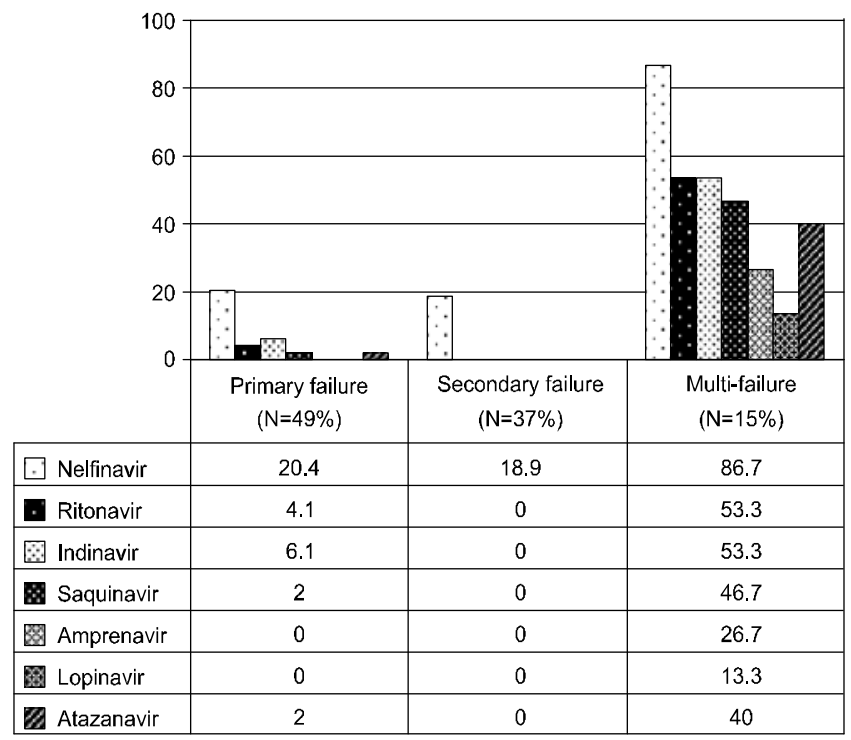

Figure 2. Resistance profile of the NRTIs after genotypic analysis using the stanford database $(\mathrm{N}=101)$, stratified by number of therapeutic failures.

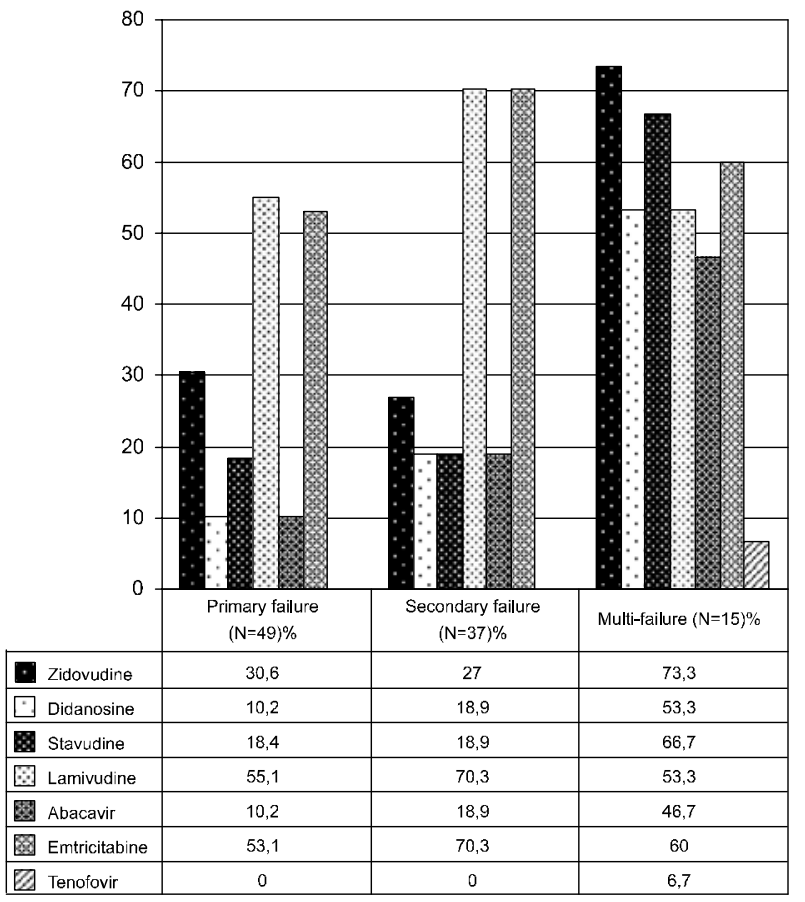


Tabela 3. Comparison of resistance profiles to the NRTI class among the therapeutic failure subgroups $(\mathrm{N}=101)$

\begin{tabular}{lcccccc}
\hline Antiretroviral & $\begin{array}{c}\text { First failure } \\
\mathbf{\%}(\mathbf{N})\end{array}$ & $\begin{array}{c}\text { Second failure } \\
\mathbf{\%}(\mathbf{N})\end{array}$ & $\begin{array}{c}\text { pvalue } \\
\mathbf{( 1}^{\text {st }} \text { and } \\
\left.\mathbf{2}^{\text {nd }} \mathbf{f a i l u r e}\right)\end{array}$ & $\begin{array}{c}\text { Multi-failure } \\
\mathbf{\%} \mathbf{( N )}\end{array}$ & $\begin{array}{c}\text { pvalue } \\
\mathbf{1}^{\text {st }} \text { and } \\
\text { anulti-failure) }\end{array}$ & $\begin{array}{c}\text { pvalue } \\
\mathbf{2}^{\text {nd }} \text { and } \\
\text { multi-failure) }\end{array}$ \\
\hline Zidovudine & $30.6(15)$ & $27(10)$ & .71 & $73.3(11)$ & .0032 & .002 \\
Didanosine & $10.2(5)$ & $18.9(7)$ & .24 & $53.3(8)$ & .001 & .019 \\
Stavudine & $18.4(9)$ & $18.9(7)$ & .94 & $66.7(10)$ & .00078 & .0022 \\
Lamivudine & $55.1(27)$ & $70.3(26)$ & .15 & $53.3(8)$ & .9 & .24 \\
Abacavir & $10.2(5)$ & $18.9(7)$ & .24 & $46.7(7)$ & .0041 & .08 \\
Emtricitabine & $53.1(26)$ & $70.3(26)$ & .1 & $60(9)$ & .63 & .52 \\
Tenofovir & $0(0)$ & $0(0)$ & 1 & $6.7(1)$ & .23 & .28 \\
Total & 49 & 37 & - & 15 & - & - \\
\hline
\end{tabular}

Statistical analysis was carried out using the Chi-square test; however, when the sample size was smaller than five we utilized the Fisher test.

Table 4. Mutation profile to the nucleoside reverse transcriptase inhibitors in the therapeutic-failure subgroups

\begin{tabular}{lccc}
\hline Resistance mutations & $\mathbf{p ~ v a l u e ~ ( 1 ~}^{\text {st }}$ and $\mathbf{2}^{\text {nd }}$ failure) & $\mathbf{p}$ value $\left(2^{\text {nd }}\right.$ and multi- failure) & p value (1 ${ }^{\text {st }}$ and multi- failure $)$ \\
\hline M41L & 0.8 & 0.003 & 0.001 \\
D67N & 0.92 & 0.52 & 0.53 \\
K70R & 0.59 & 0.08 & 0.027 \\
L210W & 0.79 & 0.00008 & 0.00001 \\
T215Y/F & 0.77 & 0.007 & 0.003 \\
K219Q/E & 0.92 & 0.08 & 0.05 \\
E44D & 0.63 & 0.06 & 0.13 \\
V118I & 0.56 & 0.16 & 0.06 \\
M184V & 0.15 & 0.24 & 0.9 \\
K65R & 0.69 & 1 & 0.56 \\
69 & 0.63 & 0.06 & 0.13 \\
\hline
\end{tabular}

Statistical analysis was carried out using the Chi-square test; however when the sample size was smaller than five we utilized the Fisher test.

Table 5. Comparison of resistance profiles against the non-nucleoside reverse transcriptase inhibitor class drugs in the therapeutic failure subgroups

\begin{tabular}{lcccccc}
\hline Antiretroviral & $\begin{array}{c}\text { First failure } \\
\mathbf{\%}(\mathbf{N})\end{array}$ & $\begin{array}{c}\text { Second failure } \\
\mathbf{\%}(\mathbf{N})\end{array}$ & $\begin{array}{c}\mathbf{p v a l u e} \\
\mathbf{( 1}^{\text {st }} \text { and } \\
\left.\mathbf{2}^{\text {nd }} \mathbf{f a i l u r e}\right)\end{array}$ & $\begin{array}{c}\text { Multi-failure } \\
\mathbf{\%} \mathbf{~ ( N )}\end{array}$ & $\begin{array}{c}\text { pvalue } \\
\mathbf{( 1}^{\text {st }} \text { and } \\
\text { multi-failure) }\end{array}$ & $\begin{array}{c}\text { pvalue } \\
\mathbf{2}^{\text {nd }} \text { and } \\
\text { multi-failure) }\end{array}$ \\
\hline Efavirenz & $36.7(18)$ & $40.5(15)$ & 0.71 & $46.7(7)$ & 0.49 & 0.68 \\
Nevirapine & $42.9(21)$ & $45.9(17)$ & 0.77 & $46.7(7)$ & 0.79 & 0.96 \\
Total & 49 & 37 & - & 15 & - & - \\
\hline
\end{tabular}

Statistical analysis was carried out using the Chi-square test; however, when the sample size was smaller than five we utilized the Fisher test.

Table 6. Evaluation of the percentage of patients with mutations to nucleoside reverse transcriptase inhibitors in the therapeuticfailure subgroups

\begin{tabular}{lccc}
\hline Resistance mutations & $\mathbf{p}$ value $\left(\mathbf{1}^{\text {st }}\right.$ and $\mathbf{2}^{\text {nd }}$ failure $)$ & $\mathbf{p}$ value $\left(2^{\text {nd }}\right.$ and multi- failure $)$ & $\mathbf{p}$ value $\left(\mathbf{1}^{\text {st }}\right.$ and multi- failure $)$ \\
\hline K103N & 0.9 & 0.73 & 0.74 \\
Y181C/I & 0.46 & 0.39 & 0.7 \\
Y188C/L/H & 1 & 0.49 & 0.55 \\
G190A/S & 0.39 & 0.7 & 0.22 \\
\hline
\end{tabular}

Statistical analysis was carried out using the Chi-square test; however when the sample size was smaller than five we utilized the Fisher test.

secondary failures and $53.3 \%$ in multi-failures). We found a low frequency of resistance to Tenofovir in all groups, though there was a high prevalence of K65R in other studies. A high degree of resistance to NVP and EFV was found in the evaluation of the NNRTI class by the number of therapeutic failures, due to the high predominance of mutations conferring cross-resistance. This was independent of the failure group, reflecting the low genetic barrier of these drugs. 
Figure 3. Resistance profile to non-nucleoside reverse transcriptase inhibitors after genotypic analysis with the stanford database $(\mathrm{N}=101)$, stratified by the number of therapeutic failures.

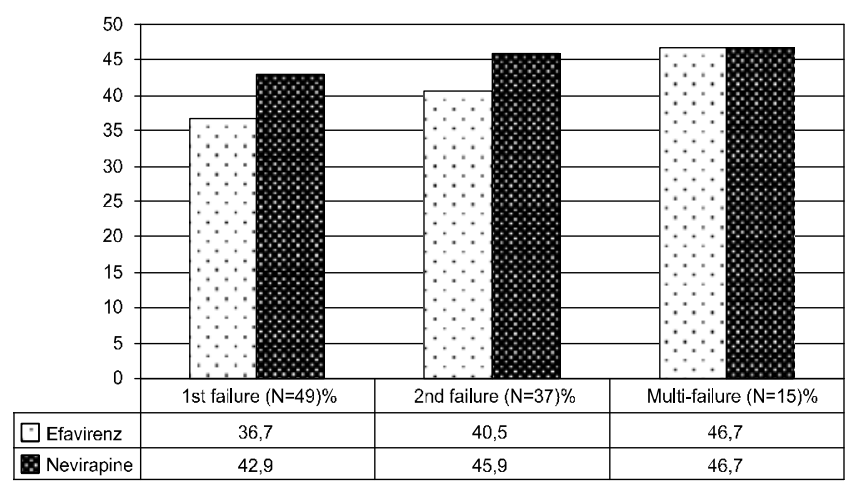

\section{Conclusions}

The frequency of resistance to most PI, NRTI and all NNRTI drugs increased in patients with increasing numbers of therapeutic failures. We conclude that the accumulation of the main resistance mutations in patients failing therapeutic regimens will affect future options for antiretroviral treatment in Brazil, since it results in a significant increase in resistance to these drugs.

\section{References}

1. Mellors J. New insights into mechanisms of HIV-1 resistance to Reverse Transcriptase Inhibitors. Program and Abstracts of the 9th Conference on Retroviruses and Opportunistic Infections; Seattle; Washington. 2002;Abstract L6. February 24-8.

2. Caride E., Brindeiro R., Hertogs K., et al. Drug-resistant reverse transcriptase genotyping and phenotyping of $\mathrm{B}$ and non-B subtypes (F and A) of human immunodeficiency virus type I found in Brazilian patients failing HAART. Virology 2000;275(1):107-15.

3. Dumans A.T., Soares M.A., Machado E.S., et al. Synonymous genetic polymorphisms within Brazilian human immunodeficiency virus type 1 subtypes may influence mutational routes to drug resistance. J Infect Dis 2004;189(7):1232-8.

4. Masquelier B., Tamalet C., Montes B., et al. Genotypic determinants of the virological response to Tenofovir Disoproxil Fumarate in nucleoside reverse transcriptase inhibitor-experienced patients. Antivir Ther 2004;9:315-23.

5. Johnson V.A., Brun-Vezinet F., Clotet B., et al. Update of the drug resistance mutations in HIV-1: 2004. Top HIV Med 2004;12(4):119-24.

6. Whitcomb J.M., Paxinos E.E., Huang W. The presence of nucleoside analogue mutations (NAMs) is highly correlated with reduced susceptibility to all NRTIs. Program and Abstracts of the 9th Conference on Retroviruses and Opportunistic Infections; Seattle; Washington. 2002;Abstract 569. February 24-8.

7. Tenorio A.R., Smith K.Y., Kuritzkes D.R., et al. HIV-1-infected antiretroviral-treated patients with prolonged partial viral suppression. J Acquir Immune Defic Syndr 2003;34(5):491-6.

8. Maia Teixeira S.L., Bastos F.I., Hacker M.A., et al. Trends in drug resistance mutations in antiretroviral-naive intravenous drug users of Rio de Janeiro. J Med Virol 2006;78(6):764-9.

9. Stoeckli T.C., Mawhinney S., Uy J., et al. Phenotypic and Genotypic analysis of biologically cloned human immunodeficiency virus type 1 isolates from patients treated with zidovudine and lamivudine. Antimicrob Agents Chemother 2002;46:4000-3.
10. Hertogs K., Bloor S., De Vroey V., et al. A novel human immunodeficiency virus type 1 reverse transcriptase mutational pattern confers phenotypic lamivudine resistance in the absence of mutation 184V. Antimic Agent Chem 2000;44:568-73.

11. D’Arminio-Monforte A., Perno C.F., Cozzi-Lepri A., et al. Low prevalence of primary mutations associated with drug resistance in antiviral-naive patients at therapy initiation. AIDS 2002;16:619-24.

12. Shafer R. Genotypic testing for HIV-1 drug resistance. Clin Microbiol Rev 2002;15:247-77.

13. Whitcomb J.M., Parkin N.T., Chappey C., et al. Broad Nucleoside Reverse-Transcriptase Inhibitor Cross-Resistance In Human Immunodeficiency Virus Type 1 Clinical Isolates. J Infect Dis 2003;188(7):992-1000.

14. Quinn J.B., Rousseau F.S., Wakeford C., et al. Prospective randomized trial of Emtricitabine versus lamivudine short-term monotherapy in human immunodeficiency virus-infected patients. J Infect Dis 2003;188:1652-8.

15. Harrigan P.R., Stone C., Griffin P., et al. Resistance profile of the human immunodeficiency virus type 1 reverse transcriptase inhibitor Abacavir (1592u89) after monotherapy and combination therapy. Cna2001 Investigative Group. J Infect Dis 2000;181:912-20.

16. Schapiro J., Turner D., Oliveira M., et al. V106m Mutation in HIV-1 clade $C$ viruses exposed to Efavirenz confers crossresistance to non-nucleoside reverse transcriptase inhibitors. AIDS 2003;17:F1-F5.

17. Brenner B., Routy J.P., Quan Y., et al. Persistence of multidrugresistant HIV-1 in primary infection leading to superinfection. AIDS 2003;18:1653-60.

18. Vasudevachari M.B., Zhang Y.M., Imamichi H., et al. Emergence of protease inhibitor resistance mutations in human immunodeficiency virus type 1 isolates from patients and rapid screening procedure for their detection. Antimic Agents and Chemother 1996;40:2535-41.

19. Tanuri A., Vicente A.C., Otsuki K., et al. Genetic variation and susceptibilities to protease inhibitors among subtype B and F isolates in Brazil. Antimicrob Agents Chemother 1999;43(2):253-8.

20. Kozal M.J., Shah N., Shen N., et al. Extensive polymorphisms observed in HIV-1 clade B protease gene using high-density oligonucleotide arrays. Nat Med 1996;2:753-9.

21. Sa-Ferreira J.A., Brindeiro P.A., Chequer-Fernandez S., et al. Human immunodeficiency virus-1 subtypes and antiretroviral drug resistance profiles among drug-naive Brazilian blood donors. Transfusion 2007;47(1):97-102.

22. Caride E., Hertogs K., Larder B., et al. Genotypic and phenotypic evidence of different drug-resistance mutation patterns between $B$ and non-B subtype isolates of human immunodeficiency virus type 1 found in Brazilian patients failing HAART. Virus Genes 2001;23(2):193-202.

23. Squires K., Mc Callister S., Lazzarin A., et al. Tipranavir/Ritonavir (Tpv/R) demonstrates a robust resistance profile in multiple protease inhibitor-experienced patients: correlation of baselinegenotype and antiviral activity in $\mathrm{Bi}$ 1182.52. (Poster 812) The 2nd International AIDS Society Conference on HIV Pathogenesis and Treatment 2003; July 14.

24. Stanford University, Palo Alto, California. Accessed in February; 2005. Http://Hivdb.Stanford.Edu/Pages/Documentpage/Drm.Html.

25. Winters M.A., Baxter J.D., Mayers D.I., et al. Frequency of antiretroviral drug resistance mutations In HIV-1 strains from patients failing triple drug regimens. The Terry Beirn Community Programs for Clinical Research on AIDS. Antivir Ther 2000;5:57-63.

26. Tanuri A., Caride E., Dantas M.C., et al. Prevalence of mutations related to HIV-1 antiretroviral resistance in Brazilian patients failing HAART. J Clin Virol 2002;25:39-46.

27. Pedroso C., Netto E.M., Figueiredo R., et al. Evaluation of the genotypic pattern of HIV-1 resistance in AIDS patients failing antiretroviral therapy. Braz J Infect Dis 2004;8(4):281-9.

28. Machado D.M., Fernandes S.C., Succi R.C., et al. Analysis of HIVtype 1 protease and reverse transcriptase in Brazilian children failing highly active antiretroviral therapy (HAART). Rev Inst Med Trop Sao Paulo 2005;47(1):1-5. 